\title{
Agreement between commercial assays for haptoglobin and serum amyloid $A$ in goats
}

\author{
Michał Czopowicz ${ }^{1 *} \mathbb{D}$, Olga Szaluś-Jordanow², Marcin Mickiewicz , Agata Moroz ${ }^{1}$, Lucjan Witkowski , \\ Iwona Markowska-Daniel ${ }^{1}$, Daria Reczyńska ${ }^{3}$, Emilia Bagnicka ${ }^{3}$ and Jarosław Kaba ${ }^{1}$
}

\begin{abstract}
Haptoglobin (Hp) and serum amyloid A (SAA) are considered as the major acute phase proteins (APPs) in goats. These APPs have been investigated in several studies during the last decade. In most studies, a colorimetric assay for $\mathrm{Hp}$ and a solid phase sandwich ELISA for SAA have been used for quantification. In 2015, reference intervals for APPs were determined using a new type of assay, the competitive ELISA (CELISA). Results obtained by the cELISA differed significantly from results obtained by previously used assays. The present study aimed to assess the agreement between so far used assays and cELISAs. Sera of 152 female dairy goats of two Polish national breeds were analysed. The concentration of $\mathrm{Hp}$ was determined using a colorimetric assay (Hp-CA) and the cELISA (Hp-cELISA), while a solid phase sandwich ELISA (SAA-sELISA) and the cELISA (SAA-cELISA) were used to measure SAA. Agreement between test results was assessed by preparing Bland-Altman plots, and analyzing $95 \%$ limits of agreement (LoA). Finally, the assays for $\mathrm{Hp}$ and SAA were compared using 147 and 138 serum samples, respectively, as 5 and 14 paired measurements, respectively, were excluded from agreement analyses to avoid extrapolation of $\mathrm{Hp}$ and SAA concentration. Measurements obtained by the Hp-CA and Hp-cELISA showed weak positive correlation $(r=0.24, P=0.003)$. Limits of agreement (LoA) ranged from $+1.6(95 \% \mathrm{Cl} 1.4$ to 1.8$) \mathrm{g} / \mathrm{L}$ to $-1.5(95 \% \mathrm{Cl}-1.7$ to -1.3$) \mathrm{g} / \mathrm{L}$. Measurements yielded by the SAA-sELISA and SAA-cELISA did not correlate $(r=-0.01, P=0.855)$. LoA ranged from $+14.5 \mathrm{mg} / \mathrm{L}$ ( $95 \% \mathrm{Cl} 12.9$ to 16.1$)$ to $-8.5 \mathrm{mg} / \mathrm{L}(95 \% \mathrm{Cl}-10.1$ to -6.9$)$. Agreement between the two types of commercial assays for determination of $\mathrm{Hp}$ and SAA concentrations in goats is poor and cELISAs tend to underrate both Hp and SAA concentrations.
\end{abstract}

Keywords: Acute phase proteins, ELISA, Small ruminants

\section{Findings}

Haptoglobin (Hp) and serum amyloid A (SAA) are the major acute phase proteins (APPs) in goats [1] and a significant increase of either Hp or SAA concentrations or both has been shown in parasitic [2-4] and bacterial $[5,6]$ infections as well as in non-infectious conditions [7-9]. For quantification, most of these studies employed a colorimetric assay for $\mathrm{Hp}$ (Hp-CA) and a solid phase sandwich ELISA for SAA (SAA-sELISA). Hp levels in healthy goats used as controls in these studies consistently remained below $0.5 \mathrm{~g} / \mathrm{L}$, whereas SAA levels varied

\footnotetext{
*Correspondence: mczopowicz@gmail.com

${ }^{1}$ Laboratory of Veterinary Epidemiology and Economics, Faculty of Veterinary Medicine, Warsaw University of Life Sciences,

Nowoursynowska 159c, 02-776 Warsaw, Poland

Full list of author information is available at the end of the article
}

considerably from $<1$ to $>150 \mathrm{mg} / \mathrm{L}$. A common drawback to all these studies was the small sample size ranging from six to 26 individuals. In 2015, competitive ELISAs (cELISAs) were introduced for quantification of $\mathrm{Hp}$ (HpcELISA) and SAA (SAA-cELISA). By using the cELISAs on a group of 50 clinically healthy goats, Heller and Johns [10] found levels of Hp and SAA that differed from previously recognized reference values. By using the cELISAs, a Hp level of $0.4-1.2 \mathrm{~g} / \mathrm{L}$ was considered normal as was a SAA level ranging from 0.4 to $2.1 \mathrm{mg} / \mathrm{L}$. In particular, the upper limit for SAA was surprising as it was even 100fold lower than observed before and what is regarded as normal in cattle and sheep [11]. On the other hand, in cattle and sheep Hp concentration above $1 \mathrm{~g} / \mathrm{L}$ had so far been considered as the unspecific hallmark of severe inflammation [12]. The findings by Heller and Johns [10] 
were supported by those of another study [13], which we carried out in pregnant goats using the same cELISAs that yielded almost similar results. Therefore, we decided to assess the agreement between the so far used assays for Hp and SAA, and cELISAs.

Sera of 152 dairy female goats of Polish White Improved and Polish Fawn Improved breeds were used. The goats were kept in three herds in western Poland, where they were housed in concrete buildings on straw bedding and did not have access to pasture. Feeding was based on hay, haylage or corn silage, and wheat and oat. The goats' age ranged from 3 to 9 years with a mean $( \pm \mathrm{SD})$ of $5.0 \pm 1.4$ years. They were blood sampled in July 2014 (51 goats) and again in July 2015 (101 goats) during a routine serological monitoring for small ruminant lentivirus (SRLV) infection. Following collection, blood was kept overnight at $4{ }^{\circ} \mathrm{C}$, then centrifuged at $3000 \mathrm{rpm}$ for $10 \mathrm{~min}$, and partitioned into three $2 \mathrm{~mL}$ serum aliquots. One sample was screened for SRLV infection using a whole-virus ELISA (ID Screen MVV/CAEV indirect-screening test; ID.vet Innovative Diagnostics, France), and the two others were frozen at $-20{ }^{\circ} \mathrm{C}$ until analysis. Blood collection was approved by the 3rd Local Ethical Committee in Warsaw (Approval No. 31/2013, 22 May 2013).

The Hp concentration was determined in each serum sample by using two commercial tests: (1) a Hp-CA PHASE $^{\text {TM }}$ RANGE Haptoglobin kit, Tridelta Development Ltd., Ireland) and (2) a Hp-cELISA (Goat haptoglobin Hpt/HP ELISA kit, Cusabio Wuhan Huamei Biotech Co., Ltd., China). Sera were diluted 1:2 for the $\mathrm{Hp}-\mathrm{CA}$ and 1:30,000 for the Hp-cELISA. Given that the lowest and the highest concentrations of calibrators used were 0 and $2.5 \mathrm{~g} / \mathrm{L}$, respectively in the $\mathrm{Hp}-\mathrm{CA}$, and 0 and $1 \mathrm{mg} / \mathrm{L}$, respectively in Hp-cELISA, the lower and upper limits of standard curves ranged from 0 to $5 \mathrm{~g} / \mathrm{L}$ in the $\mathrm{Hp}$-CA and from 0 to $30 \mathrm{~g} / \mathrm{L}$ in the Hp-ELISA. Inherent imprecision (random error, inter-assay coefficient of variation, CV\%) was $5.7 \%$ for the Hp-CA and $10 \%$ for the HpcELISA according to manufacturers' manual.

The SAA concentration was determined in each serum sample also by using two commercial tests: (1) a solid phase sandwich ELISA (SAA-sELISA) (PHASE ${ }^{\mathrm{TM}}$ RANGE multispecies SAA ELISA kit, Tridelta Development Ltd., Ireland;) and (2) a SAA-cELISA (Goat serum amyloid A SAA ELISA kit, Cusabio Wuhan Huamei Biotech Co., Ltd., China;). Sera were diluted 1:100 for the SAA-sELISA and undiluted sera were used in SAA-cELISA. Given that the lowest and the highest concentrations of calibrators used were 0 and $0.3 \mathrm{mg} / \mathrm{L}$, respectively in SAA-sELISA and 0 and $8 \mathrm{mg} / \mathrm{L}$, respectively in SAA-cELISA, the lower and upper limit of standard curves ranged from 0 to $30 \mathrm{mg} / \mathrm{L}$ in SAA-sELISA and from 0 to $8 \mathrm{mg} / \mathrm{L}$ in
SAA-cELISA. CV\% was $12.1 \%$ for the SAA-sELISA and $15 \%$ for the cELISA according to manufacturers' manual.

All assays were performed and results interpreted according to manufacturers' manuals except for sera dilution, which was chosen to fit the standard curve. The optical density was read by an Epoch Microplate Spectrophotometer (BioTek, Winooski, VT, USA) with an upper limit of 4.0. The analyses were performed in December 2016 so the samples had been stored at $-20{ }^{\circ} \mathrm{C}$ for 17 months (101 samples) or 29 months (51 samples). Before use, the assay kits had been stored in a refrigerator at $2-8{ }^{\circ} \mathrm{C}$. All assays were performed by the same person (MC). Hp analyses were done on December 7th and SAA assays on December 8th. Serum samples were taken out of the freezer the day before testing and thawed at $4{ }^{\circ} \mathrm{C}$ in a refrigerator. Then, the required serum dilutions for the $\mathrm{Hp}$ assays were prepared on non-coated Nunc ${ }^{\circledR}$ MicroW$\mathrm{ell}^{\mathrm{TM}} 96$ well polystyrene U-plates plates (Merck KGaA, Darmstadt, Germany), and undiluted serum samples were immediately returned to a refrigerator and stored overnight. The Hp-CA was immediately performed (took roughly $1 \mathrm{~h}$ ), followed by the Hp-cELISA (took roughly $2.5 \mathrm{~h}$ ). On the next day, the procedure was repeated for the SAA assays: dilution was prepared for the SAAsELISA and undiluted sera were transferred onto noncoated polystyrene U-plates and left altogether for $1 \mathrm{~h}$ to reach room temperature. Then, the SAA-sELISA was performed, followed by the SAA-cELISA (each took roughly $2.5 \mathrm{~h}$ ).

Hp and SSA concentrations yielded by each assay were reported as a median, interquartile range and range. One-sample Student's $t$ test and a Pearson's linear correlation coefficient ( $r$ ) were used to assess the difference between measurements yielded by assays from each pair. The inherent imprecision of both methods $\left(\mathrm{CV} \%_{\text {both }}\right)$ was calculated according to the formula: $\left(\mathrm{CV}{ }^{2}{ }_{\text {assay } 1}+\mathrm{CV} \%^{2}{ }_{\text {assay } 2}\right)^{1 / 2}$, where $\mathrm{CV} \%$ assay1 or 2 stood for an individual inherent imprecision (random error, inter-assay coefficient of variation) of each assay. The $95 \%$ acceptance limits based on inherent imprecision of both assays were given as: $0 \pm 1.96 \times \mathrm{CV}_{\text {both }} \times$ the mean value of the two assays according to [14]. Agreement between test results was assessed by preparing a line of equality plot and a Bland-Altman plot (a difference against mean plot or a bias plot), and analyzing 95\% limits of agreement (LoA) with their $95 \%$ confidence intervals $(95 \% \mathrm{CI})$ according to [15]. All statistical tests were two-sided and a significance level $(\alpha)$ was set at 0.05 . Statistical analysis was performed using Statistica 12 (StatSoft Inc., Palo Alto, CA, USA).

Seventy-five goats (49.0\%) tested positive for SRLV infection and 51 of these had evident carpal arthritis (33.6\% of all goats). The upper limit of reliable detection 
of Hp in the Hp-CA (> 5.0 g/L) was exceeded in five samples (values: 5.2, 7.0, 7.1, 10.7, and $12.1 \mathrm{~g} / \mathrm{L}$ ). Similar, the upper limit for SAA in the SAA-sELISA (> $30 \mathrm{mg} / \mathrm{L}$ ) was exceeded in 14 samples (values: 34.0, 34.7, 35.7, 36.2, 38.0, 39.3, 41.1, 45.5 and six samples were $>47.8 \mathrm{mg} / \mathrm{L}$ ). These measurements (and their counterparts in cELISAs) were therefore excluded from the analysis of assay agreement, so that these measurements in which $\mathrm{Hp}$ or SAA concentration was obtained by extrapolation from the standard curve were not used. Finally, the assays for $\mathrm{Hp}$ and SAA were compared using 147 (152 minus the aforementioned five) and 138 (152 minus the aforementioned 14) paired measurements, respectively (Table 1 ).

The inherent imprecision of the two assays $\left(\mathrm{CV} \%_{\text {both }}\right)$ was $11.5 \%$ for Hp assays and $19.3 \%$ for SAA assays.

Table 1 Haptoglobin (Hp) and serum amyloid A (SAA) concentration in 147 and 138 goat serum samples, respectively

\begin{tabular}{llcc}
\hline $\begin{array}{l}\text { Acute phase } \\
\text { protein }\end{array}$ & Unit & \multicolumn{2}{l}{$\begin{array}{l}\text { Concentration (median, interquar- } \\
\text { tile range, range) }\end{array}$} \\
\cline { 3 - 4 } & & cELISA & Other assays $^{\mathbf{a}}$ \\
\hline Haptoglobin & $\mathrm{g} / \mathrm{L}$ & $\begin{array}{c}0.47,0.36-0.61 \\
(0.16-1.36)\end{array}$ & $\begin{array}{c}0.26,0.24-0.31 \\
(0.21-4.89)\end{array}$ \\
Serum amyloid A & $\mathrm{mg} / \mathrm{L}$ & $\begin{array}{c}0.46,0.39-0.54 \\
(0.24-2.1)\end{array}$ & $\begin{array}{c}0.59,0.41-4.10 \\
(0.29-28.70)\end{array}$ \\
\hline
\end{tabular}

a PHASE ${ }^{\mathrm{TM}}$ RANGE Haptoglobin kit (Tridelta Development Ltd., Ireland) for $\mathrm{Hp}$, and PHASE ${ }^{\mathrm{TM}}$ RANGE multispecies SAA ELISA kit (Tridelta Development Ltd., Ireland) for SAA
Measurements yielded by the $\mathrm{Hp}-\mathrm{CA}$ and the $\mathrm{Hp}$ cELISA showed weak positive correlation $(\mathrm{r}=0.24$, $\mathrm{P}=0.003)$ and the mean difference did not differ significantly from $0(0.05 \mathrm{~g} / \mathrm{L}, 95 \% \mathrm{CI}-0.08,0.18 \mathrm{~g} / \mathrm{L}$; $\mathrm{P}=0.446)$. As a result the $95 \%$ acceptance limits based on inherent imprecision of both assays were $\pm 0.1 \mathrm{~g} / \mathrm{L}$. However, 95\% of measurements were expected to differ between these two assays by $\pm 1.6 \mathrm{~g} / \mathrm{L}$, which is a much higher figure than acceptable. Along with increasing Hp concentration in a sample, the discrepancy between measurements increased, specifically the cELISA tended to underrate $\mathrm{Hp}$ concentration compared to the colorimetric assay (Fig. 1).

The agreement between the SAA-sELISA and the SAA-cELISA was even worse. Measurements by these two assays did not correlate at all $(\mathrm{r}=-0.01, \mathrm{P}=0.855)$ and the mean difference differed significantly from 0 $(3.0 \mathrm{mg} / \mathrm{L}, 95 \%$ CI 2.1, $3.9 \mathrm{mg} / \mathrm{L} ; \mathrm{P}<0.001)$. As a result, the $95 \%$ acceptance limits based on inherent imprecision of both assays were $\pm 0.8 \mathrm{mg} / \mathrm{L}$. However, $95 \%$ of measurements of the SAA-sELISA were expected to be from $14.5 \mathrm{mg} / \mathrm{L}$ higher to $8.5 \mathrm{mg} / \mathrm{L}$ lower than those of the SAA-cELISA. The discrepancy between measurements was significantly higher than acceptable. It also increased with increasing SAA concentration in a sample, and again the cELISA tended to underrate the SAA concentration compared to the sELISA (Fig. 2); however, this tendency was much stronger than for the Hp assays. Furthermore, lack of correlation meant that measurements
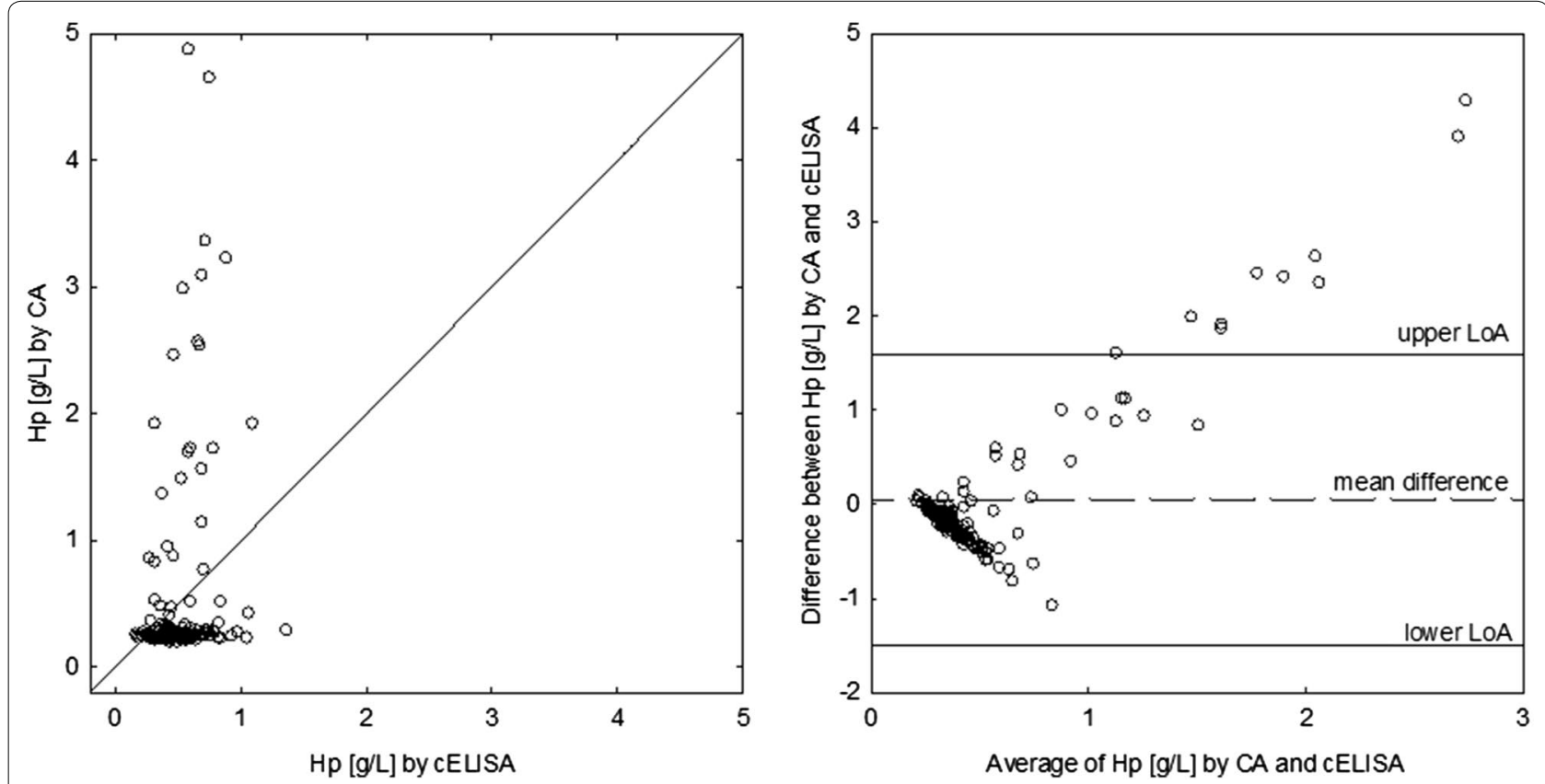

Fig. 1 A line of equality plot and a Bland-Altman plot for 147 measurements of haptoglobin ( $\mathrm{Hp}$ ) obtained using a colorimetric assay (CA) and a competitive ELISA (CELISA) in goats. LOA stands for $95 \%$ limits of agreement 

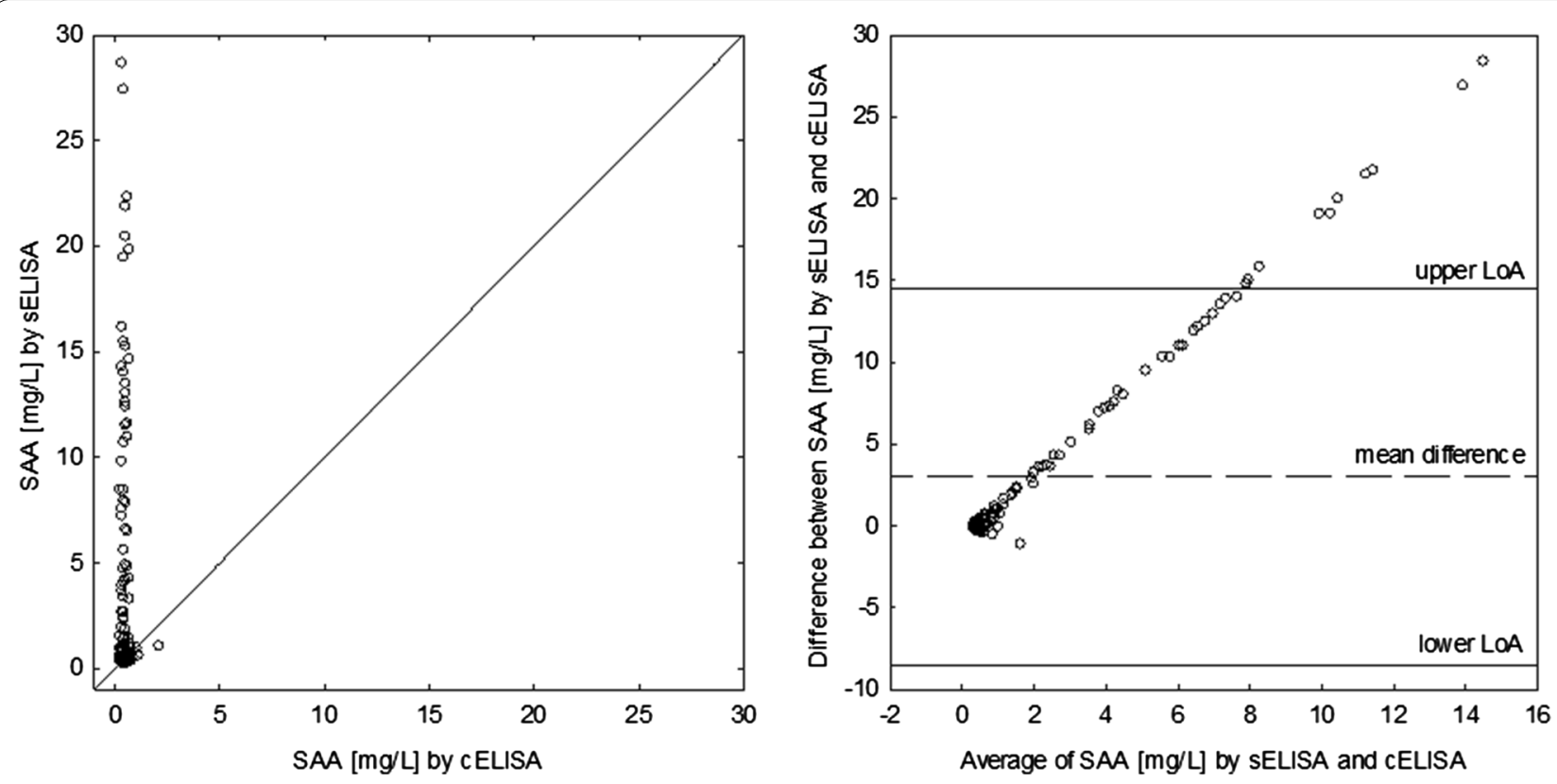

Fig. 2 A line of equality plot and Bland-Altman plot for 138 measurements of serum amyloid A (SAA) obtained using a sandwich ELISA (sELISA) and a competitive ELISA (cELISA) in goats. LoA stands for $95 \%$ limits of agreement

of one assay could not be predicted using measurements of the another assay. Detailed results of the four assays are presented in Additional file 1.

The disparity between results obtained by the two assays' is unacceptable from a clinical standpoint given the reference intervals, which are much narrower than the diversity of results obtained. Obviously, the study does not determine which of the two assays that yielded true results; potentially both could be inaccurate. Therefore, further studies are needed to estimate the accuracy of both methods, preferably by comparing with other available laboratory methods.

Three issues need further discussion. First, the HpcELISA kit used in this study was close to expiry date (analyses done on December 8th while expired on December 14th). This might have accounted for slightly lower figures obtained by this assay; however no significant decline in the assay's capability to quantify the substance should occur within the validity period, especially given that all three assays were stored in conditions consistent with manufacturers' recommendations. Second, serum samples had been stored much longer than recommended (1 year for the Hp-CA and Hp-sELISA and 1 month for both cELISAs). This undoubtedly could have reduced concentrations of Hp and SAA [16, 17], however this should not affect the agreement between the assays. This study did not aim to determine the accuracy of the two assays (an extent to which they conform to the true level) but their agreement (an extent to which their results conform to each other) [18]. Even if the results on a given serum sample are utterly false, e.g. due to a time-related decrease in the substance concentration, they are supposed to remain similar. Unfortunately, they proved to be very different. Finally, the sample dilution used in the Hp-cELISA $(1: 30,000)$ was much higher than the initial dilution recommended by the manufacturer (1:500). This increased dilution was based on our previous experience [13]: the Hp-cELISA is a competitive inhibition assay in which color intensity correlates negatively with the $\mathrm{Hp}$ concentration, i.e. the higher $\mathrm{Hp}$ concentration in the sample the lighter color in the well of ELISA plate. When we used the recommended dilution of 1:500 or even dilutions several-fold higher, the wells used to remain colorless (which we interpreted as too high concentration of $\mathrm{Hp}$ in the well). Only at dilutions of 1:18,000 [13] or higher, wells containing different samples started to differ in color intensity. However, it must be stressed that reaching such a high dilution requires a several-step procedure and, despite the fact that we did our utmost to be precise, it may have adversely affected obtained results. One premise, which may substantiate these doubts is that in other studies [1-9], Hp level quantified using Hp-CA used to be below $0.5 \mathrm{~g} / \mathrm{L}$ in healthy goats, while in the study using Hp-cELISA [10] it was between 0.4 and $1.2 \mathrm{~g} / \mathrm{L}$. The Hp-cELISA therefore appeared to overrate the $\mathrm{Hp}$ concentration compared to Hp-CA. Our observations were contrary. Unfortunately, the dilutions used were not reported by Heller and Johns [10]. Therefore, this issue requires further investigation. 
Agreement between the two types of commercial assays determining $\mathrm{Hp}$ and SAA concentration in serum of goats was found to be poor and cELISAs seemed to underrate both $\mathrm{Hp}$ and SAA concentrations compared to the colorimetric assay and the sandwich ELISA, respectively. This needs to be taken into consideration when Hp and SAA are quantified.

\section{Additional file}

Additional file 1. Detailed results obtained using four different assays for acute phase proteins in goats. SRLV—Small ruminant lentivirus; CAEcaprine arthritis-encephalitis; $\mathrm{Hp}$-CA — colorimetric assay for haptoglobin (Hp): SAA-sELISA—sandwich ELISA for serum amyloid A (SAA): HpcELISA—competitive ELISAs for Hp; SAA-cELISA—competitive ELISA for SAA

\section{Abbreviations}

APP: acute phase protein; CAE: caprine arthritis-encephalitis; Cl: confidence interval; $\mathrm{CV} \%_{\text {both: }}$ : inherent imprecision of both assays; $\mathrm{CV} \%_{\text {assay } 1 / 2}$ : inherent imprecision of one assay; Hp: haptoglobin; Hp-CA: a colorimetric assay for haptoglobin; Hp-cELISA: competitive ELISA for haptoglobin; LoA: limits of agreement; SAA: serum amyloid A; SAA-cELISA: competetive ELISA for serum amyloid A; SAA-sELISA: sandwich ELISA for serum amyloid A; SRLV: small ruminant lentivirus.

\section{Authors' contributions}

MC, IMD, EB and JK were responsible for conception and design of the study and performed statistical and epidemiological analysis. MC, AM, DR, LW, MM, OSJ made substantial contributions to acquisition of data. MC performed laboratory assays. MC, OSJ and LW were major contributors in writing the manuscript. JK, IMD and EB revised the manuscript critically for important intellectual content. All authors agreed to be accountable for all aspects of the work in ensuring that questions related to the accuracy or integrity of any part of the work were appropriately investigated and resolved. All authors read and approved the final manuscript.

\section{Author details}

${ }^{1}$ Laboratory of Veterinary Epidemiology and Economics, Faculty of Veterinary Medicine, Warsaw University of Life Sciences, Nowoursynowska 159c, 02-776 Warsaw, Poland. ${ }^{2}$ Division of Infectious Diseases, Department of Small Animal Diseases with Clinic, Faculty of Veterinary Medicine, Warsaw University of Life Sciences, Nowoursynowska 159c, 02-776 Warsaw, Poland. ${ }^{3}$ Institute of Genetics and Animal Breeding, Polish Academy of Sciences, Postępu 36A, Jastrzębiec, 05-552 Magdalenka, Poland.

\section{Acknowledgements}

Not applicable.

\section{Competing interests}

The authors declare that they have no competing interests.

\section{Availability of data and materials}

Detailed data available in Additional file 1.

\section{Consent for publication}

Not applicable.

Ethics approval and consent to participate

Blood collection was approved by the 3rd Local Ethical Committee in Warsaw, Poland (Approval No. 31/2013, 22 May 2013).

\section{Funding}

This work was financially supported by the National Science Center (Grant Number 2013/09/B/NZ6/03514). Publication was funded by KNOW (Leading
National Research Centre) Scientific Consortium "Healthy Animal_Safe Food", decision of Ministry of Science and Higher Education No. 05-1/KNOW2/2015.

\section{Publisher's Note}

Springer Nature remains neutral with regard to jurisdictional claims in published maps and institutional affiliations.

Received: 23 June 2017 Accepted: 25 September 2017

Published online: 02 October 2017

\section{References}

1. González FH, Tecles F, Martínez-Subiela S, Tvarijonaviciute A, Soler L, Cerón JJ. Acute phase protein response in goats. J Vet Diagn Investig. 2008;20:580-4.

2. Hashemnia M, Khodakaram-Tafti A, Razavi SM, Nazifi S. Changing patterns of acute phase proteins and inflammatory mediators in experimental caprine coccidiosis. Korean J Parasitol. 2011;49:213-9.

3. Hosseini A, Namazi F, Oryan A, Nazifi S. Correlation between some hematological parameters, acute phase proteins and serum immunoglobulins in experimental caprine besnoitiosis. J Parasit Dis. 2015:39:155-61.

4. Rahman MM, Lecchi C, Fraquelli C, Sartorelli P, Ceciliani F. Acute phase protein response in Alpine ibex with sarcoptic mange. Vet Parasitol. 2010;168:293-8.

5. El-Deeb WM. Clinicobiochemical investigations of gangrenous mastitis in does: immunological responses and oxidative stress biomarkers. J Zhejiang Univ Sci B. 2013;14:33-9.

6. Jeber ZK, Mohd Jin Z, Jesse FF, Saharee AA, Sabri J, Yusoff R, Wahid H. Influence of Corynebacterium pseudotuberculosis infection on level of acute phase proteins in goats. BMC Vet Res. 2016;12:48.

7. González FH, Hernández F, Madrid J, Martínez-Subiela S, Tvarijonaviciute A, Cerón JJ, Tecles F. Acute phase proteins in experimentally induced pregnancy toxemia in goats. J Vet Diagn Investig. 2011;23:57-62.

8. Jia YY, Wang SQ, Ni YD, Zhang YS, Zhuang S, Shen XZ. High concentrateinduced subacute ruminal acidosis (SARA) increases plasma acute phase proteins (APPs) and cortisol in goats. Animal. 2014;8:1433-8.

9. Karademir U, Akin I, Erdogan H, Ural K, Asici GS. Effect of Ketoprofen on acute phase protein concentrations in goats undergoing castration. BMC Vet Res. 2016;12:123.

10. Heller MC, Johns JL. Acute phase proteins in healthy goats: establishment of reference intervals. J Vet Diagn Investig. 2015;27:177-81.

11. Tóthová C, Nagy O, Kováč G. Acute phase proteins and their use in the diagnosis of diseases in ruminants: a review. Vet Med. 2014;59:163-80.

12. Skinner JG, Brown RA, Roberts L. Bovine haptoglobin response in clinically defined field conditions. Vet Rec. 1991:128:147-9.

13. Czopowicz M, Szaluś-Jordanow O, Mickiewicz M, Witkowski L, Markowska-Daniel I, Stefaniak T, et al. Acute-phase proteins in pregnant goats: a longitudinal study. J Vet Diagn Investig. 2017. doi:10.1177/1040638717714295.

14. Jensen AL, Kjelgaard-Hansen M. Method comparison in the clinical laboratory. Vet Clin Pathol. 2006;35:276-86.

15. Bland JM, Altman DG. Statistical methods for assessing agreement between two methods of clinical measurement. Lancet. 1986;1:307-10.

16. Gutiérrez AM, Martínez-Subiela S, Cerón JJ. Evaluation of changes in haptoglobin and C-reactive protein concentrations caused by freezing of saliva and meat juice samples collected from healthy and diseased pigs. Am J Vet Res. 2011;72:11-7.

17. Tóthová C, Nagy O, Seidel H, Kováč G. The effect of storage temperature and time on the concentrations of bovine serum amyloid $\mathrm{A}$ and its mammary associated isoform. Vet Med Int. 2012;2012:861458.

18. Thrusfield M. Veterinary epidemiology. 3rd ed. Ames: Blackwell Publishing; 2007. 